\title{
Algumas considerações sobre a posição da arte nos Cursos de Estética de Hegel $^{1}$
}

\section{Some considerations about art to position in Aesthetics Courses of Hegel}

\author{
Danilo Franco Maimone \\ Graduando, Departamento de Filosofia e Metodologias da Ciência, Universidade Federal de São Carlos \\ - UFSCar, São Carlos, SP, Brasil.
}

\begin{abstract}
Resumo: Ao considerar que a determinação do conceito tem seu fundamento na ideia, Hegel, nos Cursos de Estética, mostra a efetividade da consciência-de-si e para-si ao enfatizar a apreensão da natureza pelo espírito, de modo que o conceito de natureza é determinado pela ideia. O conceito de bela arte, nesse domínio, coincide com o campo do "Espírito Absoluto" e esta determinação posiciona a arte ao lado da religião e da filosofia. Desse modo, identificamos aqui duas questões pertinentes ao estudo que está sendo realizado: quais as razões de Hegel para posicionar a arte como primeiro momento do "Espírito Absoluto" e como se dão as relações entre arte e religião e entre arte e filosofia.

Palavras-chaves: ideia, bela arte, filosofia, conceito, consciência.

Abstract: When considering that the determination of the concept has its foundation in the idea, Hegel, in Aesthetics Courses, shows the effectiveness consciousness of self and to itself when emphasizing the seizure of nature by spirit, in a way that the concept of nature is determined by the idea. The concept of fine art, in this domain, matches with the "Absolute Spirit" field and this determination positions the art beside religion and philosophy. Thereby, we identified here two relevant related to the study that is being conducted: which reasons Hegel position art as first moment of the "Absolute Spirit" and how are the relations between art and religion, and art and philosophy.
\end{abstract}

Keywords: ideas, fine arts, philosophy, concept, conscience.

\footnotetext{
${ }^{1}$ Texto apresentado no VI Encontro de Pesquisa na Graduação em Filosofia da UFSCar, campus de São Carlos, em 2014.
} 
Hegel se refere à arte como uma ciência e, não obstante a isso, propõe uma filosofia da arte. Certamente os motivos estabelecidos nas Lições sobre a Estética revelam a inadequação do termo estética ao designar o conceito apenas como ciência dos sentidos, da sensação e da percepção, traduzidos pela derivação dos termos aisthanesthai e aisthesis. Nota-se também a inadequação do termo kallística, que deriva do termo grego kallos, traduzido por "belo", pois se refere tão somente ao belo na arte, mas não da beleza em geral.

A alternativa é propor uma ciência que pensasse tanto a arte quanto o espírito, uma filosofia da arte ou mais precisamente filosofia da bela arte, que não apenas compreende o desmembramento do espírito na efetividade como arte, mas também que vislumbra seus conceitos.

A partir dessa denominação, identificamos duas questões, às quais o presente texto procura responder: quais as razões de Hegel para posicionar a arte como primeiro momento do "Espírito Absoluto" e como se dão as relações entre arte e religião, e entre arte e filosofia? É preciso não perder de vista que não se trata apenas da sensibilidade desprovida de consciência de si, mas, sobretudo, da retomada nessa sensibilidade que efetiva o espírito absoluto.

O texto do presente trabalho está estruturado conforme foram identificados os temas que aqui são desenrolados em função de algumas problemáticas: oposição entre natureza e espírito, belo, liberdade e, por fim, a posição da arte frente à religião e à filosofia.

\section{Apreensão da natureza pelo espírito: momento da consciência em si e para si}

De acordo com Hegel, a beleza não pode ser tomada como abstração do entendimento, mas um conceito em si mesmo do concreto e absoluto, isto é, a efetividade da ideia, na medida em que é saber verdadeiro. Noutro sentido, trata-se da ideia absoluta em sua aparição adequada a ela mesma. O que está em jogo é a tese filosófica de que o verdadeiro é conceituável, já que seu fundamento é justamente a ideia, e essa é a exigência para que possamos conhecer filosoficamente sobre a arte, mais precisamente a bela arte.

Há duas implicações nessa afirmação: a primeira é que o conceito não é a mesma coisa que espírito absoluto, já que aquele é determinado por este; a segunda e não menos importante é que Hegel utiliza duas terminações equivalentes, a saber, ideia e absoluto. O conceito pode ser compreendido como a determinidade verdadeira, abstrata e unilateral da representação ou do pensamento, portanto ele é posto no objeto, enquanto que o espírito absoluto é a ideia que determina o verdadeiro.

Essas definições iniciais abrem margem para discutirmos a oposição entre Espírito e Natureza, ou de outro modo, finitude e infinitude. As duas concepções são essenciais na mesma medida, mas é a relação que as difere, visto que a natureza se mantém na posição de ter sido posta pelo espírito absoluto, já que este é propriamente o saber. Em todo caso, por se tratar de uma atividade absoluta, o espírito distingue outro de si, que é a própria natureza e traz em si a ideia. A verdade da Natureza é o espírito como idealidade e negatividade, as quais constituem o conceito de subjetividade do espírito.

A limitação ou a finitude do espírito encontra-se justamente no momento em que está em relação com sua existência como saber e vontade, enquanto subjetivo, isto é, enquanto o sujeito não é objetivado. Mas ao apreender a própria finitude, conquista sua infinitude. Trata-se aqui propriamente do espírito absoluto, pois se efetiva como negatividade absoluta, já que coloca sua finitude em si mesmo e a supera, tornando-se para si mesmo. Em linhas gerais, há uma unificação, dada na 
apreensão das consequências singulares finitas, isto é, a superação da finitude, de modo que realiza o espírito absoluto num saber de si mesmo ou a consciência de si (em si e para si) e, no sentido mais amplo, alcança a natureza.

\section{Determinação do conceito de belo artístico ou bela arte}

A determinação do conceito de bela arte observa Hegel, tem seu fundamento na ideia ou no espírito que é saber em si e para si, tornando-se absoluto. O processo explicita o momento da consciência-de-si ao enfatizar a apreensão da natureza pelo espírito, mostrando que o conceito de natureza é determinado pela ideia. Mesmo que os objetos da arte não sejam naturais, o modo de produzi-los é natural, e isso se deve a apreensão da natureza pelo espírito.

Tal proposição aproxima Hegel da Crítica da Faculdade do Juízo de Kant, porém os conhecimentos em ambos são diferentes. A bela arte em Kant é produzida pelo gênio sem, contudo, estabelecer nenhuma determinação, já Hegel vai além da ausência de determinação de modo que, para a arte conferir o estatuto de bela, é necessário a exposição da verdade presente no espírito absoluto. Destarte, Kant enfatiza que “[...] a natureza era bela se ao mesmo tempo parecia ser arte e, a arte só é bela se temos consciência que é arte e que parece ser natureza [...]" (KANT, 1995, p. 152).

A arte enquanto aparência de natureza é o ponto de aproximação referido acima entre Kant e Hegel. Todavia, é necessário ter em vista que para Hegel o espírito apreende a natureza e transforma a oposição em reconciliação, de modo que transfigura o natural na arte, consistindo em determinação da beleza. Assim, é necessário nos orientarmos para as determinações do belo artístico, as quais podemos dizer que pertencem à esfera da ideia, sem permanecer preso a conhecimentos e fatos do espírito enquanto finito. A ênfase é que o campo da bela arte coincide com o campo do espírito absoluto e essa determinação posiciona a arte ao lado da religião e da filosofia.

Esse posicionamento ocorre na ocasião em que Hegel defende a superioridade do belo artístico sobre o belo natural, pois a natureza é determinada pelo espírito, conforme vimos acima. Essa superação é caracterizada por posicionar a arte no âmbito da ideia, de modo a considerar o belo como representação artística (Darstellung) do espírito na arte, que se apresenta. Uma das coisas que atesta a beleza numa obra de arte é justamente a representação que se distingue da mera expressão, identificada, sobretudo, como forma e também um conjunto de regras e normas, que em geral teria a função apenas imitativa das sensações. Uma expressão artística pode não conter o conteúdo do espírito, que é o verdadeiro, e não ser considerada bela.

As observações desenvolvidas por Hegel nos Cursos de Estética, mesmo atentas a esse critério, apontam para a necessidade de pensar o conceito de belo artístico, pois já sabemos que suas determinações são dadas no espírito. Mas seu conceito apresenta algumas exigências: a primeira é que se configura por um conteúdo, uma finalidade e um significado; a segunda faz referência à expressão, isto é, ao fenômeno e a realidade deste conteúdo. A representação artística (Darstellung) ocorre na conjunção entre conteúdo e expressão, cujo o exterior e o particular aparecem como manifestação do interior.

Todavia, essas exigências a princípio teleológicas, conduzem a investigação para o âmbito prático, sobretudo porque Hegel, ao estabelecer os conceitos de conteúdo e significado como se referindo ao que é em si mesmo simples, afasta num primeiro momento e reconcilia num segundo momento, abstração e concreto. Por abstração podemos entender, segundo o próprio Hegel, como a simplicidade correspondente ao tema proposto na arte, o qual constitui o fundamento da execução, já o concreto é uma espécie de extensão da abstração caracterizada pela execução. O processo 
se desenrola da seguinte maneira: o significado abstrato considerado apenas como conteúdo tem em si mesmo a determinação de chegar à execução e se tornar concreto.

Essa determinação introduzida pelo espírito faz essencialmente que surja um dever que, inicialmente, identifica uma necessidade não satisfeita e uma insuficiência do sujeito, a qual tem a aspiração de superar-se e caminhar para a satisfação. Esse dever é a tensão que está no meio da necessidade e da satisfação tensão que se supera quando o conteúdo, primeiramente subjetivo se coloca e, logo após, a exigência em objetivar o subjetivo, noutro sentido, tornar-se universal. "O mundo dos nossos fins e interesses espirituais repousa nessa objetivação para encontrar satisfação." (HEGEL, 2001, p. 111).

\section{Conteúdo supremo do espírito absoluto}

A realidade efetiva pode ser compreendida como a resultante do processo de transformação e não um dado imutável, isto é, trata-se do próprio movimento das coisas tomadas em seu devir. O movimento se constitui por unidades dos diferentes momentos ${ }^{2}$, em que cada um é a negação do precedente; dessa maneira, é necessário pensar a unidade e a identidade da origem e do fim.

Trata-se de pensar ainda nesse processo a objetivação do ser que sai de si, torna-se para si, para retornar a si, isto é, chegar a si pela mediação do que não é si, estabelecendo a consciência-em-si e para si através da negação ou do movimento dialético. Esse processo referido é próprio do que Hegel chama de sujeito e opõe à substância, categoria metafísica que designa, ao contrário, a imutabilidade eterna. Desse modo, a identidade do verdadeiro, do racional e do real podem ser categorias que exprimem a unidade do Espírito em seu devir efetivo.

Segundo Gérard Bras (1990, p. 20), o espírito em si e para si realiza o seu mundo e, a partir de si mesmo, torna-se efetivo e livre porque se relaciona consigo mesmo. A liberdade deve ser compreendida como a determinação suprema do espírito, de modo que se trata de uma capacidade pela qual o subjetivo é capaz de abranger em si mesmo.

Essa noção permite desmembrar sua constituição, inicialmente dada no aspecto formal, cujo sujeito nada tem de estranho ${ }^{3}$, desprovido de fronteiras e limites. O sujeito nesse ponto está reconciliado com o mundo, isto é, as contradições e as contraposições estão solucionadas ou ao menos adormecidas.

De modo preliminar, na medida em que a liberdade é subjetiva e não executada, se coloca perante o sujeito a não liberdade, que pode ser compreendida como aquilo que é objetivo enquanto necessidade natural e, imediatamente, essa contraposição deve ser reconciliada. Ainda na esfera da subjetividade, Hegel mostra que, por um lado, a liberdade é em si mesmo universal e autônoma, cujo conteúdo é a racionalidade, mas por outro lado, trata-se dos impulsos dos homens (paixões, sentimentos, inclinações), tudo o que o coração concreto do homem contém em si mesmo.

Todavia é importante ressaltar que o homem aspira satisfação e liberdade no saber (espírito) e na vontade. O impulso do desejo de saber decorre da superação da relação de não liberdade e de se apropriar do mundo na representação e no pensamento.

\footnotetext{
${ }^{2}$ A noção de momento, segundo o professor Gérard Bras não se refere a uma disposição temporal, mas ao sentido que dão os físicos quando falam de um momento de uma força em relação a um ponto, conceito este que permite determinar o movimento de um mecanismo simples (BRAS, 1990, p. 20).

${ }^{3} \mathrm{O}$ termo estranhamento é elucidado por Gérard Bras como alienação (Ibidem, p. 11). Segundo Hegel, esse estranhamento é a atividade da consciência que, saindo de si mesma para se fazer outra, isto é, uma realidade objetiva, produz algo que se desprende dela e lhe opõe. Essa noção é fortuita para compreendermos a efetividade do espírito na arte, determinado pela liberdade.
} 
Esse momento de apropriação se esclarece na arte e disso resulta a convergência entre arte e filosofia.

Mesmo sob esse registro da superação e da apropriação, o conteúdo da liberdade ainda permanece limitado e mantém o aspecto de finitude. Hegel recorre ao argumento mundano para mostrar as razões, ao considerar que a vida do Estado, cuja liberdade na ação parte do fato de que a razão da vontade encontra efetividade. $\mathrm{O}$ argumento constitui novamente unilateralidade e abstração, pois se trata apenas da liberdade racional da vontade que na vida no Estado se explicita.

Hegel enfatiza essa perspectiva do Estado única e exclusivamente para explicar que o homem, de modo geral, busca satisfação no mundo, o que esclarece de modo livre a oposição sujeito e objeto. Essa oposição é de tal modo a exigência ou o dever de objetivar-se e, assim, alcançar a satisfação.

Os direitos e deveres não são suficientes, sendo meramente aspectos finitos. O ser humano procura uma verdade mais elevada, em que as contradições e as contraposições da finitude podem encontrar sua solução e a liberdade sua completa satisfação. Apreender esse conceito da verdade é tarefa da filosofia, que penetra nas determinações que se contradizem, conhecendo-as segundo seus conceitos (como não sendo absolutas em sua unilateralidade).

Nesse caso, a arte para se tornar bela deve representar essa verdade mais elevada que a filosofia alcança e repousa no âmbito da liberdade. A filosofia certamente conhece o conceito que, segundo Hegel, "é pensamento conceitual", portanto, verdadeiro. Entretanto é preciso observar que conceito e verdade em si são coisas diferentes, simplesmente pela unilateralidade que o conceito traz consigo e pela sua determinidade, dada pela ideia.

Se vislumbrarmos a efetividade finita, cujo espírito ainda não determinou a natureza, a verdade aparece como uma separação daquilo que, segundo sua verdade, é inseparável. Ilustremos com o seguinte exemplo: o sujeito humano finito e a natureza orgânica que o envolve. Já o conceito contém esses aspectos, mas aparecem de modo reconciliados. Interessa saber se o conceito, em conformidade com sua verdade, também será efetivo nessa unidade e se as contraposições não persistem umas com as outras, mas apenas valham como momentos ideais, reconciliados numa livre sintonia.

\section{Variações do espírito absoluto}

A elaboração hegeliana do conceito de arte, essencialmente, visou reconciliar a razão e a sensibilidade, não numa síntese, mas na ideia determinada não por si mesma, mas por seu conteúdo concreto, isto é, a liberdade. Também reconciliou os saberes empíricos da arte com a definição de um ideal de belo, que não está separado das obras de arte. A arte, de modo geral, forma uma unidade que carrega consigo a verdade mais elevada, própria do espírito absoluto e determinada pela liberdade, a qual encontra plena satisfação.

O filósofo francês Charles Bérnard observa que Hegel (2003) recorre a alguns exemplos como a poesia de Homero, as tragédias de Sófocles, as comédias de Aristófanes, as catedrais góticas, os dramas de Shakespeare, as pinturas de Rafael, entre outros, com a finalidade de articular a lógica do conceito da arte, cuja verdade é relativa aos aspectos particular, singular e universal ${ }^{4}$. Sobre esses aspectos é importante ressaltar que não estão desvinculados da liberdade que constitui a ideia, assim como caracterizam as expressões do espírito absoluto nos objetos artísticos.

\footnotetext{
${ }^{4}$ Particular, singular e universal são aspectos estabelecidos por Hegel na introdução dos Cursos de Estética, os quais podem ser denominados como modelos necessários para uma teoria poética dos gêneros da arte (HEGEL, 2001).
} 
A arte, para Hegel, é caracterizada como o primeiro momento do espírito absoluto. Segundo Gerd Bornhein (1994, p. 130), a razão única para estabelecer essa posição inferior à religião e à filosofia está no modo deficiente de a arte se relacionar com o ideal, em função de sua ligação ao sensível. A verdade teria um sentido de correção, pois necessariamente adequa a representação ao objeto artístico. Noutro sentido, estabelece concordância entre objeto e o conceito de ideia.

O verdadeiro na medida em que é objeto absoluto da consciência, em concordância com o sensível ou na arte, faz com que ela pertença à dimensão absoluta do espírito e, nesse sentido, encontra-se no mesmo terreno que a religião e a filosofia, mas diferentemente da religião, a beleza carrega em si a ideia que é representada nos objetos artísticos.

Desse modo, existem três dimensões do espírito absoluto que são apenas diferenciados segundo suas Formas, sob as quais trazem à consciência seu objeto, isto é, o espírito absoluto: arte, religião e filosofia. Segundo Hegel, as diferenças dessas Formas encontram-se no próprio espírito. A explicação oferecida pelo filósofo nos conduz a formas de apreensão da finitude, na sua essencialidade; de outro modo, podemos dizer que apreende a si mesma naquilo que é essencial de si e com isso vem a ser absoluta.

A arte é o primeiro momento do espírito porque sua forma de apreensão é imediata, por isso sensível, um saber na Forma (Form) e na Figura (Gestalt) do próprio sensível e objetivo, na qual o absoluto chega à intuição e à sensação. O segundo momento do espírito é a religião, cuja forma de apreensão está na consciência que representa ${ }^{5}$, isto é, na interioridade do sujeito; e o terceiro momento é a filosofia, em que a forma de apreensão conceitual é a liberdade de pensamento do espírito absoluto.

Expressões artísticas apresentam à consciência a verdade no modo de configuração sensível. A dialética hegeliana pode ser observada sob esse primeiro âmbito, pois o espírito absoluto, já na consciência em si e para si, se mostra de modo sensível na arte, estabelecendo negatividade naquilo que o precede, determinando realidade efetiva. Portanto, a intuição sensível pertence à arte. Neste modo de aparição há um sentido e um significado mais altos e profundos, sem tornar apreensível, através do meio sensível, o conceito em sua universalidade, já que, segundo Hegel, a essência do belo é a unidade do conceito como fenômeno individual, que também contém a produção artística.

Desse modo, essa unidade que também se produz no elemento da representação artística (Darstellung) também se exterioriza no elemento da expressão sensível, especialmente na poesia, cuja exterioridade artística é desprovida de matéria. A poesia é tratada por Hegel como a arte mais "espiritualizada", porque, além de ser destituída de matéria, o espírito absoluto manifesta-se diretamente, portanto, contém a união entre significado e sua configuração individual e assim cada conteúdo é apreendido imediatamente e levado à representação.

As ilustrações hegelianas do processo de efetivação do espírito absoluto através da sensibilidade da arte parecem apontar para uma nova dificuldade, a qual sugere um círculo que ultrapassa seus modos de apreensão e de exposição do absoluto, pois a arte em si ainda possui um limite, a saber, o sensível. Na análise histórica e sistemática-processual do problema do sensível, Hegel observa que há uma espécie de antes e depois na arte, em que primeiramente ocorre representação sensibilizante dos aspectos divinos e, em seguida, a oposição ou a negação desses aspectos. Por esse motivo, precisamos compreender o segundo âmbito, que é a religião.

\footnotetext{
${ }^{5}$ A representação na religião não é a mesma da Darstellung ou representação artística. Hegel estabelece que são representações distintas, pois a representação na religião refere-se a interioridade do sujeito, enquanto que a Darstellung a representação que se apresenta do espírito absoluto na arte. Por isso traduzimos o termo "Darstellung" como apresentação (Idem, 2002).
} 
Assim como a arte, a religião tem como forma de sua consciência a representação, na medida em que o absoluto está transferido da objetividade da arte para a interioridade do sujeito, de sorte que a subjetividade interior se torna o momento principal. A devoção não pertence à arte enquanto tal, mas depende dela para que se interiorize como forma pura, mas não suprema.

Hegel mostra que a religião se serve da arte para aproximar a verdade religiosa da sensação ou para tornar plástica a fantasia. Isso pode ser observado nas artes denominadas simbólicas, por exemplo, a arquitetura que majestosamente criou seus templos para que as divindades pudessem ocupá-los. O mesmo ocorre na escultura, representada quase sempre por divindades, que ocupam os templos arquitetônicos, como também dos poetas gregos que criaram seus deuses e deram o conteúdo determinado da religião.

Esses exemplos figuram os modos como a arte atende os interesses religiosos, e isso não significa dizer que, na sua totalidade, a devoção religiosa seja o principal. Esse modelo é visto historicamente, primeiro entre os gregos e depois no cristianismo, mas em geral a arte expressa um saber mais elevado, a ideia. Isso indica que o conceito de arte não deve estar vinculado ao conceito de religião, já que as exigências dessa última são apenas atendidas pela primeira. Mas Hegel estabelece uma superioridade da religião em função de sua proximidade com o espírito absoluto ser maior que a sensibilidade da arte, mas isso é questionável, pela sua arbitrariedade. Teríamos que considerar necessariamente a religião e seu conteúdo.

O terceiro âmbito e, sem dúvida, a forma mais pura do saber: a filosofia. Trata-se de um livre pensar, cuja ciência leva o mesmo conteúdo (espírito absoluto) à consciência por meio do pensamento sistemático, se apropria e apreende o que antes só é conteúdo da sensação (arte) ou representação subjetiva (religião).

Hegel aponta que na filosofia estão unidos os dois outros âmbitos, a arte e a religião. Por um lado, a objetividade da arte substituiu a sensibilidade exterior pela forma suprema, isto é, o pensamento (Gedanken) e, por outro lado, a subjetividade da religião que foi purificada na subjetividade do pensar (Denken). Pela expressão Gedanken, compreendemos que se trata de pensamento objetivado e intuitivo, já pela expressão Denken, compreendemos como pensar ativo e subjetivo.

Essas duas Formas estão contidas na filosofia, mas o pensar se subdivide da seguinte maneira: há uma subjetividade mais interior e própria e também o verdadeiro (Ideia), em que simultaneamente a universalidade é a mais objetiva e, apenas no pensamento, pode apreender-se na Forma de si.

A relação entre arte e filosofia parece ser mais forte que a relação entre arte e religião, embora Hegel não considere esse sentido, pela proximidade ao absoluto. Arte e filosofia se relacionam na ideia objetiva, cuja determinação é a liberdade. A liberdade já não ocorre na religião, já que Deus seria o conteúdo supremo. Essa contradição não se resolve nos textos da Fenomenologia do Espírito, como também na Enciclopédia das Ciências Filosóficas, cujo tema da arte aparece.

Disso decorre que Hegel não tenha se dado conta do enfraquecimento da relação arte e religião, justamente porque ocorre uma ruptura da universalidade com a particularidade - aspectos que delineavam a arte do passado - as quais eram representadas no elemento do divino. Essa ruptura conduziu à cultura de reflexão, conforme Gerd Bornhein mostra apontando para a precedência, por exemplo, do barroco em relação ao rococó e, cujo movimento reflexivo, já era presente na época de Hegel.

Entretanto, o problema da reflexão aparece nos estudos sobre a poesia, ocasião em que Hegel vai tratar da expressão poética, a qual é constituída por signos. O círculo das representações é expandido na medida em que se introduz a reflexão, levando a poesia a alcançar uma posição distinta da música e, mais precisamente, da dicção. A caracterização do problema conduz a expressão poética a distanciar-se 
da linguagem prosaica, a fim de se elevar a plenitude do espírito, a algo novo, capaz de despertar o interesse.

A mencionada dissociação, como a problematização da reflexão torna emblemático o tema da morte da arte, inevitavelmente parte do processo dialético, mas que no sentido concreto enseja novas expressões, representações e reflexões da arte $^{6}$ (BORNHEIM, 1994, p. 132).

Assim, o aspecto de superioridade da religião sobre a arte seria apenas de ordem metodológica, pelo fato de não se referir ao aspecto sensível, mas de uma subjetividade mais interior e própria. Portanto, conclui-se que a arte atende tanto os interesses da religião, quanto da filosofia, mas, sobretudo, aos interesses espirituais.

Correspondência: Danilo Franco Maimone. Universidade Federal de São Carlos - UFSCar, Rodovia Washington Luís, Km 235, s/n, Jardim Guanabara, CEP 13565-905, São Carlos, SP, Brasil.

Conflito de interesses: Nenhum.

Todos os autores leram e aprovam a versão final submetida a revista Em curso.

\footnotetext{
${ }^{6} \mathrm{O}$ tema da morte da arte refere-se ao momento de dissolução inevitável do processo dialético, o estabelecimento da oposição, i.e., a consciência em si e para si retorna a si por intermédio da negação do processo dialético que na negatividade abre a possibilidade da arte se restabelecer de outra forma. Isso não significa dizer que seja o fim da arte em geral, mas apenas um movimento.
} 


\section{Bibliografia}

BORNHEIM, G. O que está vivo e o que está morto na estética de Hegel. In: NOVAES, A. Artepensamento. São Paulo: Companhia das Letras, 1994.

BRAS, G. Hegel e a arte: uma apresentação à Estética. Tradução Maria Luiza X. de A. Borges. Rio de Janeiro: Jorge Zahar Editor, 1990.

HEGEL, G. W. F. Estética. Tradução Orlando Vitorino e Álvaro Ribeiro. Lisboa: Guimarães Editores, $1972.7 \mathrm{v}$.

HEGEL, G. W. F. Cursos de estética. 2. ed. Tradução de Marco Aurélio Werle. São Paulo: Edusp, 2001. 4 v.

HEGEL, G. W. F. Fenomenologia do Espírito. Tradução de Paulo Menezes com a colaboração de Karl-Heinz Efken e José Nogueira Machado. Petrópolis: Vozes, 2002.

HEGEL, G. W. F. Introduction aux Leçons d'Esthétique. Tradução francesa de Charles Bérnard. Paris: Nathan, 2003.

HENRICH, D. The contemporany relevance of Hegel's aesthetics. In: STERN, R. G. W. F. Critical assesments. Londres: Routledge, 1993.

KANT, I. Crítica da Faculdade do Juízo. 2. ed. Tradução de Valério Rohden e Antonio Marques. São Paulo: Forense Universitária, 1995. 